\title{
Imaging and modelling of poly(3-hydroxybutyrate) synthesis in Paracoccus denitrificans
}

Sergio Bordel ${ }^{1,2}$ (D) Rob J. M. van Spanning ${ }^{3}$ and Fernando Santos-Beneit ${ }^{1,2,3^{*}}$ (1)

\begin{abstract}
Poly(3-hydroxybutyrate) (PHB) granule formation in Paracoccus denitrificans Pd1222 was investigated by laser scanning confocal microscopy (LSCM) and gas chromatography analysis. Cells that had been starved for 2 days were free of PHB granules but resynthesized them within 30 min of growth in fresh medium with succinate. In most cases, the granules were distributed randomly, although in some cases they appeared in a more organized pattern. The rates of growth and PHB accumulation were analyzed within the frame of a Genome-Scale Metabolic Model (GSMM) containing 781 metabolic genes, 1403 reactions and 1503 metabolites. The model was used to obtain quantitative predictions of biomass yields and PHB synthesis during aerobic growth on succinate as sole carbon and energy sources. The results revealed an initial fast stage of $\mathrm{PHB}$ accumulation, during which all of the acetyl-CoA originating from succinate was diverted to PHB production. The next stage was characterized by a tenfold lower PHB production rate and the simultaneous onset of exponential growth, during which acetyl-CoA was predominantly drained into the TCA cycle. Previous research has shown that PHB accumulation correlates with cytosolic acetyl-CoA concentration. It has also been shown that PHB accumulation is not transcriptionally regulated. Our results are consistent with the mentioned findings and suggest that, in absence of cell growth, most of the cellular acetyl-CoA is channeled to PHB synthesis, while during exponential growth, it is drained to the TCA cycle, causing a reduction of the cytosolic acetyl-CoA pool and a concomitant decrease of the synthesis of acetoacetyl-CoA (the precursor of PHB synthesis).
\end{abstract}

Keywords: Poly-3-hydroxybutyrate (PHB), Polyhydroxyalkanoates (PHA), Storage inclusions, Nile Red, LSCM, Metabolic modelling, Acetyl-CoA

\section{Key points}

Modelling PHB synthesis, imaging the onset of PHB granules and their localization

\section{Introduction}

Various microorganisms accumulate polyhydroxyalkanoates (PHAs) when carbon and energy sources are readily available. These polymers serve as reserves of carbon and energy to allow cell survival during starved

\footnotetext{
*Correspondence: fernando.santos.beneit@uva.es

1 Department of Chemical Engineering and Environmental Technology, School of Industrial Engineering, University of Valladolid, Dr. Mergelina, $s / n, 47011$ Valladolid, Spain

Full list of author information is available at the end of the article
}

conditions (Jendrossek and Handrick 2002). They have attracted industrial interest because they are completely biodegradable, non-toxic, biocompatible and naturally produced (Anderson and Dawes 1990; Dariš and Knez 2020). Paracoccus denitrificans, a gram-negative bacterium, accumulates poly(3-hydroxybutyrate) (PHB) as insoluble granules inside the cell (Ueda et al. 1992). PHB is the most prominent member of the PHAs and one of the best-studied bacterial storage polymers (Jendrossek 2009). Biosynthesis and biodegradation of PHB and other PHAs have been extensively investigated during the last three decades (Potter and Steinbüchel 2005; Jendrossek and Pfeiffer 2014). One exciting outcome of these studies was the finding that PHB granules are
Springer Open
C The Author(s) 2021. Open Access This article is licensed under a Creative Commons Attribution 4.0 International License, which permits use, sharing, adaptation, distribution and reproduction in any medium or format, as long as you give appropriate credit to the original author(s) and the source, provide a link to the Creative Commons licence, and indicate if changes were made. The images or other third party material in this article are included in the article's Creative Commons licence, unless indicated otherwise in a credit line to the material. If material is not included in the article's Creative Commons licence and your intended use is not permitted by statutory regulation or exceeds the permitted use, you will need to obtain permission directly from the copyright holder. To view a copy of this licence, visit http://creativecommons.org/licenses/by/4.0/. 
complexly organized subcellular structures and appear to be more than simple polymer inclusions (Jendrossek 2009). There are controversial results on the specific subcellular localization of the PHB granules in distinct bacterial models. Many studies show microscopy images with bacterial cells full of randomly localized PHB granules (Reinecke and Steinbüchel 2009), while other studies suggest a more organized pattern of PHB granules more or less in the middle of cells (Tian et al. 2005), or in the cell periphery near the cell poles (Jendrossek 2005). The aim of this work was twofold. Firstly, the investigation of PHB synthesis in P. denitrificans by both microscopy and biochemical analyses to study pattern formation of the granules. Secondly, the application of a functional Genome-Scale Metabolic Model (GSMM) of $P$. denitrificans Pd1222 to predict the metabolic flux distributions during the initial phase of fast PHB accumulation and the subsequent phase of exponential growth. The rationale was that GSMMs are comprehensive compilations of all metabolic reactions taking place in a particular cell, and as such can be used to predict theoretical yields of a bacterium during growth on different carbon and energy sources. As a result, we estimated the rates of biomass yield and PHB formations during growth on succinate. Consequently, in this study we investigated the formation of PHB granules and subcellular localization in P. denitrificans, a denitrifying model organism with a well-documented ability to accumulate PHB.

\section{Materials and methods}

\section{Bacterial strains and growth conditions}

Paracoccus denitrificans (Pd1222 Rif ${ }^{\mathrm{R}}$, De Vries et al. 1989) was cultivated in batch cultures at $34^{\circ} \mathrm{C}$ with either vigorous shaking $300 \mathrm{rpm}$ or low shaking $(150 \mathrm{rpm})$. Cultures were performed in a defined mineral salts medium (Harms et al. 1985) containing a trace solution and $25 \mathrm{mM}$ succinate as the sole energy and carbon source. When required precultures from glycerol stocks were performed in LB supplemented with $50 \mu \mathrm{g} \mathrm{ml}{ }^{-1}$ of rifampicin. Growth of $P$. denitrificans was measured spectrophotometrically (at $660 \mathrm{~nm}$ ) using a SPECTROstar Nano spectrophotometer (BMG Labtech) and by quantifying dry weight biomass. For dry weight determination, three culture samples $(2 \mathrm{ml})$ were washed twice with MilliQ water and dried for 5 days at $80{ }^{\circ} \mathrm{C}$. When required, optical dense readings were used as a reproducible, high throughput method of growth phenotyping. Conversion of OD measurements to an estimated biomass concentration value was done as follow: Biomass $\left(\mathrm{g} \mathrm{L}^{-1}\right)=\mathrm{OD}_{660} \times 0.365 \mathrm{~g} \mathrm{~L}^{-1}$.

Initiation of PHB granule formation was performed by transfer of PHB-depleted cells to a fresh mineral salts medium with $25 \mathrm{mM}$ succinate as the sole carbon and energy sources. For the preparation and imaging of spheroplasts, the $P$. denitrificans cells at an $\mathrm{OD}_{660}$ of about 1 were first incubated with $1 \mu \mathrm{M}$ MTG for $20 \mathrm{~min}$ at $34{ }^{\circ} \mathrm{C}$ (to stain the PHB inclusions). Then, the stained cells were concentrated and washed in cold $100 \mathrm{mM}$ Tris/ $\mathrm{HCl}$ (pH 7.3), and finally resuspended in $100 \mathrm{mM}$ Tris $/ \mathrm{HCl}\left(\mathrm{pH}\right.$ 7.3) to a final $\mathrm{OD}_{660}$ of about 50 . After that, $1 \mathrm{ml}$ of the concentrated cells were treated with $50 \mu \mathrm{l}$ of protease inhibitor $+10 \mu \mathrm{l}$ of $200 \mathrm{mM}$ EDTA $+1 \mathrm{ml}$ of $200 \mathrm{mM}$ Tris $/ \mathrm{HCl}(\mathrm{pH} 7.3) / 1 \mathrm{M}$ sucrose $+40 \mu$ of lysozyme $\left(50 \mathrm{mg} \cdot \mathrm{ml}^{-1}\right)$ during $30 \mathrm{~min}$ at room temperature. Finally, a mild osmotic shock was administered by the addition of $1 \mathrm{ml}$ of ice-cold water. Spheroplasts were then centrifuged and resuspended in $100 \mathrm{mM}$ Tris/ $\mathrm{HCl}\left(\mathrm{pH}\right.$ 7.3) to a final $\mathrm{OD}_{660}$ of about 12 and then a drop of this dilution was imaged by LSCM as described in the section below. To image PHB granule formation at the desired time points, $1 \mathrm{ml}$ of culture was incubated with $2 \mu \mathrm{M}$ of Nile Red for $5 \mathrm{~min}$ at room temperature. Then, cells were washed with phosphatebuffered saline (PBS) and concentrated to a final $\mathrm{OD}_{660}$ of about 20 for microscopic analyses (see below).

\section{Fluorescent staining and laser scanning confocal microscopy (LSCM)}

Cultures were incubated with the following dyes and concentrations: (1) MitoTraker Green FM $(1 \mu \mathrm{M})$, (2) FM4-64 $(1 \mu \mathrm{M})$, (3) Nile Red $(1-2 \mu \mathrm{M})$, (4) Syto 80 $(500 \mathrm{nM})$. Bacterial samples were taken at defined time points and were immediately stained by the addition of the corresponding dye at the desire concentration and incubated for at least $5 \mathrm{~min}$ at $34{ }^{\circ} \mathrm{C}$ or room temperature. Cells were concentrated by centrifugation, washed once with PBS and normally re-suspended in PBS to a final $\mathrm{OD}_{660} \sim 20$. Bacteria were immobilized on glass by mixing a drop of a concentrated bacterial suspension with a drop of a $1 \%$ low-melted agarose solution and immediately covered by a coverslip.

Cells were visualized with a BioRad Laser Scanning System Radiance 2000 confocal microscope. Blue-Argon Laser (488 nm) excited MTG and GreenHelium/Neon Laser $(543 \mathrm{~nm})$ excited the membrane dyes and DNA dyes used in this study. Images were converted from the Bio-Rad PIC to TIFF format using the public domain software ImageJ. Images were pseudo-coloured for enhanced visualization of differences in fluorescence intensity. The Blue-Argon Laser images were pseudo-coloured to green and the Helium/ Neon images were pseudo-coloured to red. A $60 \times$ oil objective was used to take the pictures and a $10 \times$ extra zoom of the LaserSharp2000 program to magnify the size of the cells. 


\section{Analytical procedures}

The residual succinate concentration in the medium was measured by HPLC in $2 \mathrm{ml}$ of filtered supernatant samples $(0.22 \mu \mathrm{m})$ through an Alliance Waters HPLC equipped with an Aminex HPX-87H column $(7.8 \mathrm{~mm} \times 300 \mathrm{~mm})$. The mobile phase was $\mathrm{H}_{2} \mathrm{SO}_{4}$ (25 mM), the column temperature was $75{ }^{\circ} \mathrm{C}$ and the

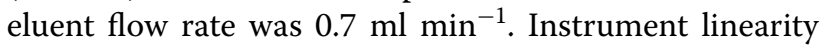
was evaluated with succinate (ReagentPlus, 99\%; SigmaAldrich) in the concentration range of $0.8-67.8 \mathrm{mM}$. The $\mathrm{R}^{2}$ obtained was 1 .

Quantitative determination of PHB was carried out by adapting the method described in Zúñiga et al. (2011). Samples of $1.5 \mathrm{ml}$ were centrifuged $(14,000 \mathrm{rpm}, 10 \mathrm{~min})$ and the supernatant was discarded. Then, $1 \mathrm{ml}$ of a solution of 1-propanol: $\mathrm{HCl}(80: 20 v / v, 37 \% \mathrm{HCl} w / v), 50 \mu \mathrm{l}$ of the internal standard (benzoic acid) in 1-propanol $\left(25 \mathrm{~g} \mathrm{~L}^{-1}\right)$ and $2 \mathrm{ml}$ of chloroform were added to the pellets and incubated for $4 \mathrm{~h}$ at $100{ }^{\circ} \mathrm{C}$ in a Thermoreaktot TR 300 (Merck KGaA, Darmstadt, Germany). After digestion, $1 \mathrm{ml}$ of deionized water was added, and the suspension was vortexed. The organic phase was collected and filtered through $0.22 \mu \mathrm{m}$ fibreglass filters. The propanly-ester of the butyric acid (the monomer constituting the PHB polymer) was measured in a 7820A GC coupled with a 5977E MSD (Agilent Technologies, Santa Clara, USA) and equipped with a DB-wax column $(30 \mathrm{~m} \times 250 \mu \mathrm{m} \times 0.25 \mu \mathrm{m})$. The detector and injector temperatures were maintained at $250{ }^{\circ} \mathrm{C}$. The oven temperature was initially maintained at $40{ }^{\circ} \mathrm{C}$ for $5 \mathrm{~min}$, increased at $10{ }^{\circ} \mathrm{C} \mathrm{min}-1$ up to $200{ }^{\circ} \mathrm{C}$ (maintained at this temperature for $2 \mathrm{~min}$ ) and then increased up to $240{ }^{\circ} \mathrm{C}$ at a rate of $5{ }^{\circ} \mathrm{C} \mathrm{min}^{-1}$. Finally, PHB values were expressed as percentage dry cell weight based on the internal standard and the standard curve of Poly (3-hydroxybutyric acid) (Sigma-Aldrich ${ }^{\circledR}$, USA).

\section{Genome-Scale Metabolic Model and FBA simulation}

The genome of P. denitrificans Pd1222 was downloaded from GenBank (GCA_000203895.1). The genome was annotated using RAST (Overbeek et al. 2005), and a draft metabolic model was generated with SEED (Overbeek et al. 2014). The initial draft was manually curated (Bordel et al. 2019a), by checking gene annotations and making sure that genes annotated as enzymes are linked to the corresponding metabolic function, as reported in the database KEGG. Model manipulations and FBA simulations were carried out using the python library COBRApy (Ebrahim et al. 2013), version 0.9.1 with python 2.7.12. FBA simulations have been carried out by setting specific growth rates and specific PHB production rates, and minimizing the succinate uptake rate, The result of this simulation provides an estimation of all the metabolic reaction rates taking place in the cells.The model in SBML format (Paracoccus_denitrificans.xml) and the associated lists of metabolites (Paracoccus_metabolites.txt) and reactions (Paracoccus_reactions.txt) in tab-separated formats, Thave been deposited in https://github.com/SergioBordel/Model Paracoccus. The RAST annotation, both in Excel and GenBank formats, have been placed in the same repository.

\section{Results \\ PHB granules formation by $P$. denitrificans cells using confocal microscopy}

The lipophilic core of PHB granules is covered by a monolayer of phospholipids (Steinbüchel et al. 1995); therefore only appropriate lipophilic dyes can be used to stain it (Vida and Emr 1995). PHB inclusions have been widely stained using Nile Red and a good linear correlation between the former and the PHB content has been well established in many previous works using different bacteria (Gorenflo et al. 1999; Spiekermann et al. 1999; Zuriani et al. 2013). P. denitrificans cells growing at the mid-exponential phase of growth were stained with different membrane dyes, including: MitoTracker ${ }^{\mathrm{TM}}$ Green FM (MTG), FM4-64 and Nile Red, and analyzed by LSCM. Figure 1 shows that both MTG and Nile Red (but not FM4-64) were able to stain the PHB granules. To our knowledge this the first time that staining of PHB inclusions is achieved using MTG (a dye normally used to stain mitochondria). No significant differences were observed between the staining patterns of Nile Red and MTG, except that the fluorescence intensity with Nile Red was stronger. The fluorescent images show that almost all of the cells growing at their exponential phase of growth contained PHB granules ranging from one to three in single cells and from two to six in dividing cells. Occasionally, we found cells with more structured and symmetric patterns of distribution of the PHB granules; see examples in Additional file 1: Figure S1A. Interestingly, this structured distribution of the PHB granules was also observed in spheroplasts of $P$. denitrificans; see examples in Additional file 1: Figure S1B.

We also carried out double-staining experiments of $P$. denitrificans cells growing at their mid-exponential phase of growth using MTG as membrane dye and Syto80 as DNA staining dye (see Fig. 1D-G). Figure 1D shows two daughter cells of a recently divided cell with PHB granules located at the poles and their DNA in the centre, indicative for mutual exclusion of these two types of molecules. 


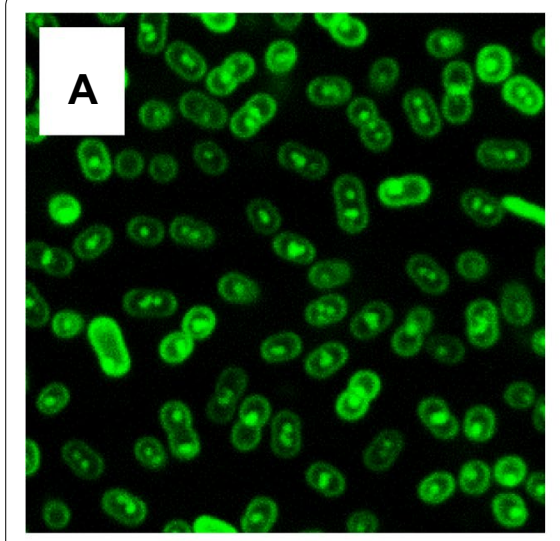

MitoTracker ${ }^{\mathrm{TM}}$ Green FM

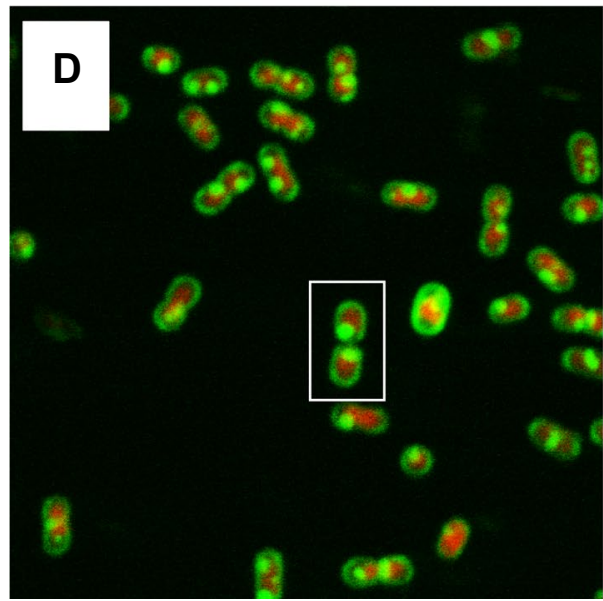

Double staining with MTG and Syto80

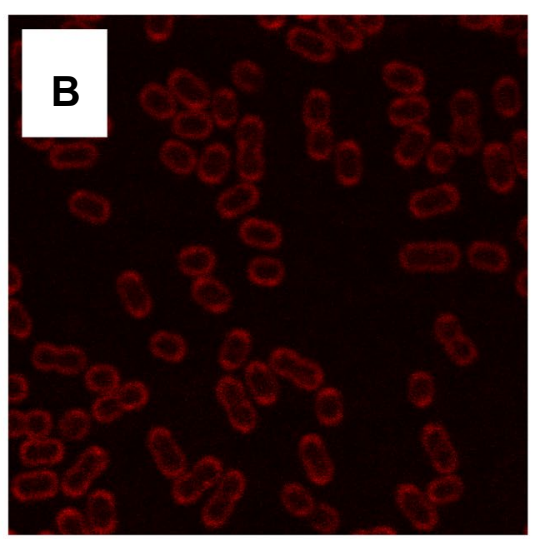

FM4-64

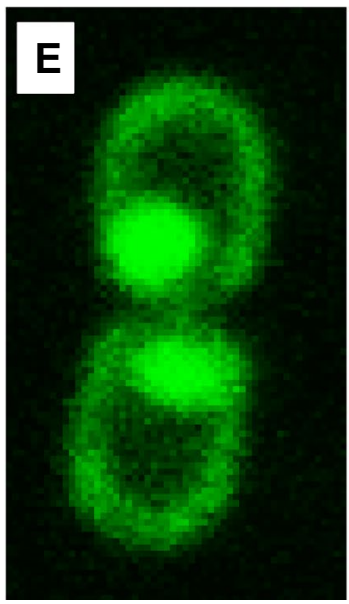

MTG

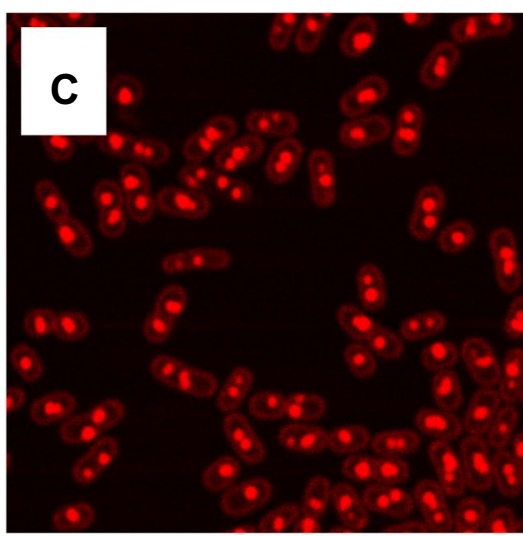

Nile Red

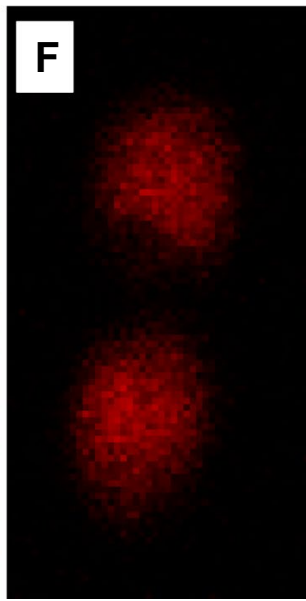

Syto80

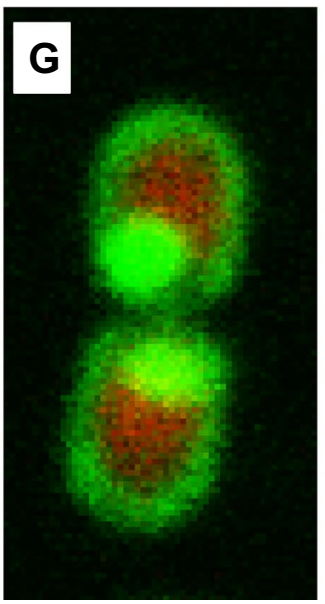

MTG+Syto80

Fig. 1 Staining of $P$. denitrificans cells with different fluorescent dyes. In all cases, cells were grown to an $O D_{660}$ of about $0.75-1$ and stained with:

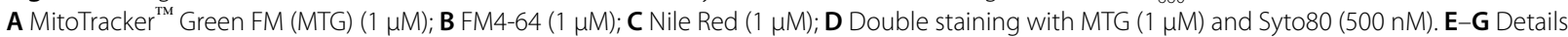
of daughter cells from a recently divided mother cell. MTG image (E), Syto80 image (F), overlay (G). Cells were imaged using two different lasers (a blue-argon Laser, $488 \mathrm{~nm}$, for excitation of MTG and a green-helium/neon laser, $543 \mathrm{~nm}$, for excitation of Syto80)

\section{PHB granules in $P$. denitrificans cells are synthesized de-novo within $30 \mathrm{~min}$}

We then investigated the kinetics of PHB accumulation in $P$. denitrificans cells during growth on mineral salts medium with succinate. A time-series experiment was performed and samples were collected periodically for simultaneous determination of biomass, PHB content and microscopic performance. We noted that the specific PHB content per dry weight biomass remained constant at a level of about $7 \%$ during the exponential phase of growth. Once at the stationary phase, the PHB granules were completely consumed within less than $25 \mathrm{~h}$, as judged by gas chromatography and microscopy analyses that show that these starved cells lack Nile
Red fluorescent foci (see Additional file 1: Figure S2). We then used these starved cells (see sample B in I of Fig. 2) as inoculum for new cultures with fresh medium and succinate. These cultures were grown at $34^{\circ} \mathrm{C}$ and samples were collected at different time points along with the early exponential phase of growth (from 30 to $165 \mathrm{~min}$; see samples T1-T4 in panel II of Fig. 2). Each sample was incubated with Nile Red for $5 \mathrm{~min}$ and imaged by LSCM to observe the presence and distribution of the PHB granules. Results are shown in Fig. 2 and they show the presence of PHB granules already at the first time point (T1), which was 30 min after the inoculation of the new cultures with the starved cells. Since the biomass did not increase in that period, we 

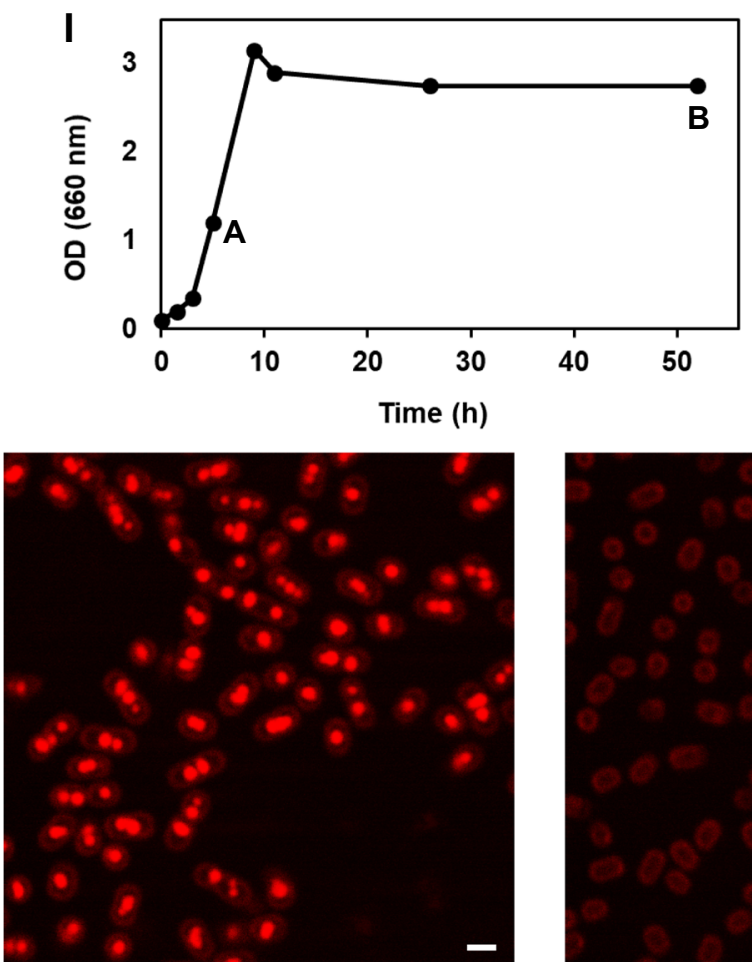

A

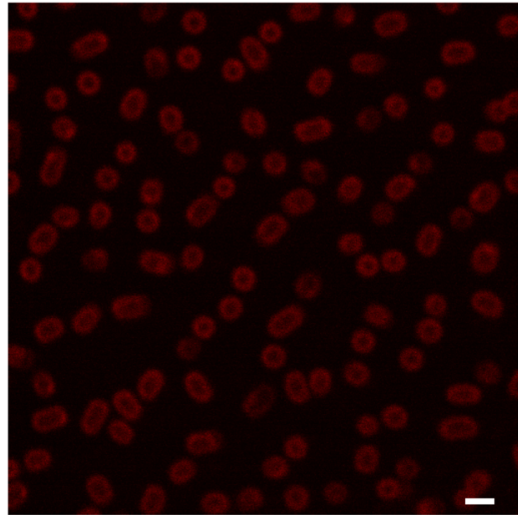

$B-T_{0}$
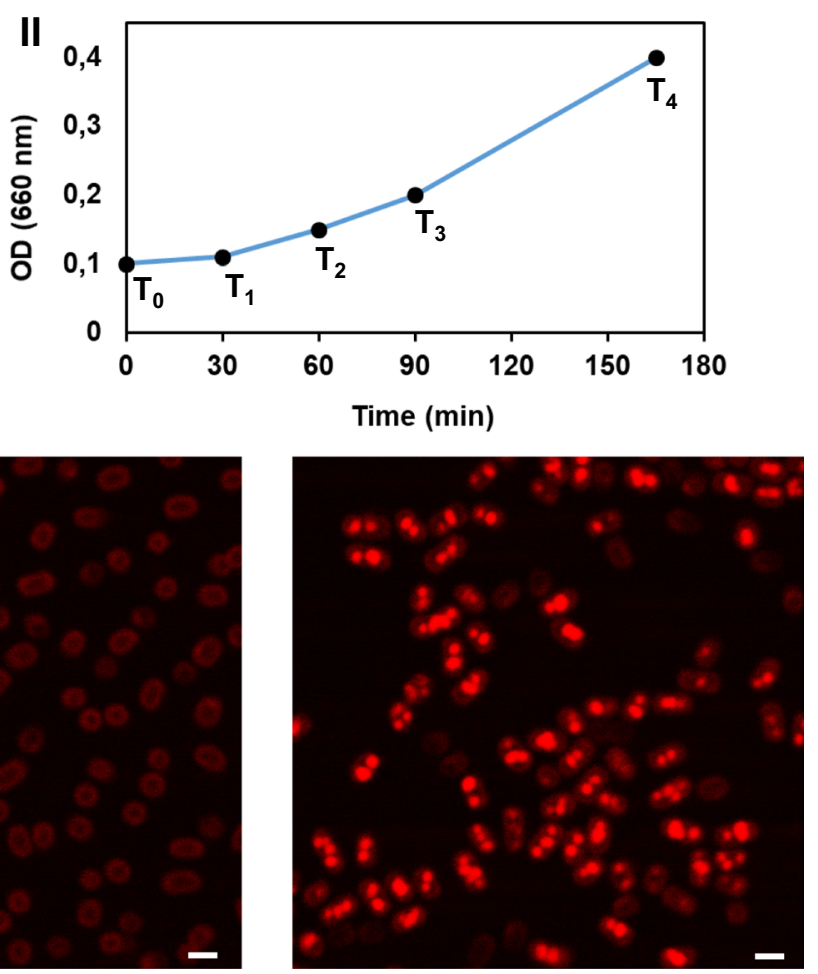

$\mathbf{T}_{1}$

Fig. 2 The PHB granules appear before the first cellular division. A Mid-exponential phase cells. B Late stationary phase cells, used as inoculum $\left(\mathrm{T}_{0}\right)$ for the second time-series experiment. $\mathrm{T}_{1}$ Cells after 30 min of shaking at $34^{\circ} \mathrm{C}$ and $300 \mathrm{rpm}$. The microscopy images of $\mathrm{T} 2, \mathrm{~T} 3$ and $\mathrm{T} 4$ samples are not shown in Fig. 2 because they are very similar to the T1 sample. The scale bar is $1 \mu \mathrm{m}$

\section{A}

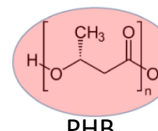

PHB

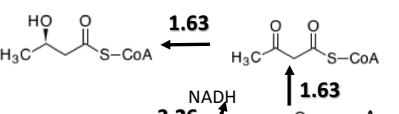$$
\text { 等 }
$$
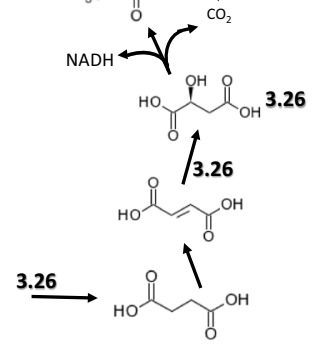

Succinic acid

\section{B}

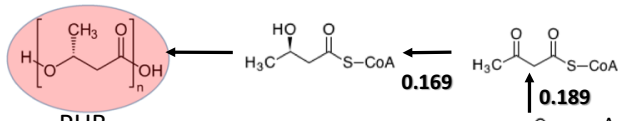

PHB

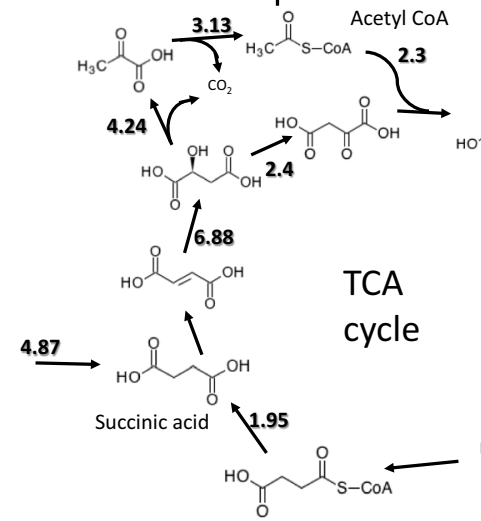

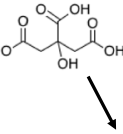

$\mathrm{HO}^{\mathrm{O}} \mathrm{OH}$ no $\mathrm{Co}$ HO

Fig. 3 Distributions of metabolic fluxes under PHB accumulation and exponential growth. The numbers are reaction rates in $\mathrm{mmol}_{\mathrm{g}-\mathrm{DW}} \mathrm{W}^{-1}$ Only the main metabolic fluxes are shown 
can conclude that PHB synthesis occurs before cellular division.

\section{Modelling PHB synthesis in P. denitrificans cells growing on succinate as sole carbon and energy sources}

To model PHB synthesis in P. denitrificans, we performed a third time series experiment using the same defined mineral salts medium with $25 \mathrm{mM}$ succinate as the sole carbon and energy and carbon sources and a similar amount of inoculum $\left(0.04 \mathrm{mg} \mathrm{ml}^{-1}\right)$, but with a lower frequency of shaking ( $150 \mathrm{rpm}$; so as not to have increase in the number of cells in the first $30 \mathrm{~min}$ of culture). Experiments were carried out in duplicate and samples were collected periodically for simultaneous determination of dry weight of the biomass, PHB content and residual concentration of succinate in the medium. Data of these analyses are shown in Table 1.

The slope of the logarithm of biomass during the exponential phase versus time showed a specific growth rate of $0.232 \pm 0.002 \mathrm{~h}^{-1}$. The slope of the produced biomass versus the consumed succinate indicates a biomass yield on succinate of $48.4 \pm 2.1 \mathrm{~g}$-DW $\mathrm{mol}^{-1}$. Dividing the specific growth rate by the yield, we obtain a specific succinate uptake rate of $4.8 \pm 0.2 \mathrm{mmol} \mathrm{g-DW}{ }^{-1} \mathrm{~h}^{-1}$. Assuming a constant PHB content of $7 \%$ during the exponential phase, the specific rate of PHB production is equal to $16.2 \mathrm{mg}$ PHB g-DW ${ }^{-1} \mathrm{~h}^{-1}$. With a molar mass of $96 \mathrm{~g} \mathrm{~mol}^{-1}$ (the mass of the monomer minus a water molecule lost during polymerization), the molar PHB

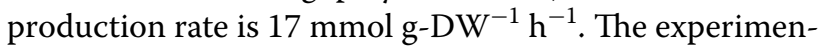
tally measured specific growth rate and PHB production rates were set as constraints in a GSMM of $P$. denitrificans. Flux Balance Analysis (FBA) was carried out by minimizing the rate of succinate uptake rate. Maintenance ATP costs were calculated from the maintenance substrate uptake rates reported by van Verseveld et al.

Table 1 Table showing dry weight biomass, PHB content and residual succinate concentration in the medium

\begin{tabular}{lllr}
\hline Time (h) & $\begin{array}{l}\text { Dry weight } \\
\text { biomass }(\mathbf{m g} \\
\mathbf{~} \mathbf{l}^{-\mathbf{1}} \text { ) }\end{array}$ & $\begin{array}{l}\text { PHB production per dry } \\
\text { weight biomass }\left(\boldsymbol{\mu g} \mathbf{~ m g ~}^{-\mathbf{1}}\right)\end{array}$ & {$[\mathbf{S u c}]_{\mathbf{m M}}$} \\
\hline $\mathrm{T}_{0}$ & $0.04 \pm 0.00$ & $00.0 \pm 0.0$ & $25.0 \pm 0.0$ \\
$\mathrm{~T}_{0.5}$ & $0.04 \pm 0.00$ & $78.4 \pm 8.4$ & $24.9 \pm 0.0$ \\
$\mathrm{~T}_{2}$ & $0.06 \pm 0.01$ & $74.6 \pm 9.1$ & $23.7 \pm 0.3$ \\
$\mathrm{~T}_{4}$ & $0.07 \pm 0.01$ & $75.0 \pm 8.3$ & $23.2 \pm 0.9$ \\
$\mathrm{~T}_{7}$ & $0.21 \pm 0.03$ & $66.7 \pm 2.7$ & $20.3 \pm 0.5$ \\
$\mathrm{~T}_{10}$ & $0.59 \pm 0.07$ & $72.3 \pm 1.4$ & $15.7 \pm 0.6$ \\
$\mathrm{~T}_{12}$ & $0.82 \pm 0.03$ & $68.9 \pm 5.4$ & $9.1 \pm 0.3$ \\
$\mathrm{~T}_{14}$ & $1.01 \pm 0.01$ & $72.4 \pm 5.4$ & $4.7 \pm 0.5$ \\
$\mathrm{~T}_{16}$ & $1.12 \pm 0.03$ & $73.6 \pm 9.3$ & $0.9 \pm 0.2$ \\
\hline
\end{tabular}

(1979) (the ordinate at the origin in Pirt's equation). A value of $7.5 \mathrm{mmol}$ ATP $\mathrm{g}$-DW ${ }^{-1} \mathrm{~h}^{-1}$ for maintenance was obtained and was imposed as an extra constraint in the model. The FBA simulation predicted a specific succinate uptake rate of 4.87, which agrees almost perfectly with the experimental result, confirming the accuracy of the used GSMM. FBA simulations yield predictions of the reaction rates for every metabolic enzyme in the model.

The PHB content increased from zero to $7.8 \%$ in $30 \mathrm{~min}$, which corresponds to a specific accumulation rate of $1.63 \mathrm{mmol} \mathrm{g-DW}{ }^{-1} \mathrm{~h}^{-1}$. This rate is ten times higher than the one observed during exponential growth. In the absence of growth, and assuming the absence of $\mathrm{CO}_{2}$ fixation by the Calvin cycle, all the consumed succinate is transformed into acetyl-CoA as is shown in Fig. 3A. The rates of synthesis of acetyl-CoA predicted by the GSMM both during the initial PHB accumulation and during exponential growth are very close (3.26 versus $\left.3.13 \mathrm{mmol} \mathrm{g-DW}^{-1} \mathrm{~h}^{-1}\right)$. This suggests that during exponential growth the rate of PHB synthesis decreases drastically due to the fact that TCA cycle enzymes consume acetyl-CoA for biosynthetic pathways necessary to support growth (Fig. 3B). According to the model, the TCA cycle remains inactive during the initial phase of $\mathrm{PHB}$ accumulation, due to the fact that the NADH obtained in the reactions catalyzed by the malic enzyme (ME) and pyruvate dehydrogenase (PDH) is sufficient to feed the respiratory chain and generate the ATP necessary for cell maintenance. The production of PHB in $P$. denitrificans correlates well with acetyl-CoA levels, with higher levels leading to higher PHB production.

The metabolic flux distributions predicted by the GSMM also revealed the number of metabolic enzymes required for PHB accumulation and ATP production in each of the phases. According to this estimation, the cell needs to express only 50 metabolic enzymes in the first PHB accumulation phase, while during the exponential growth phase, 218 different metabolic enzymes are required (see the list of these enzymes in Additional file 2: File S1).

\section{Discussion}

Here we show a sequential onset of PHB formation and remaining modes of cellular metabolism in $P$. denitrificans cells that were previously starved and lacked PHB granules. PHB granules were synthesized within $30 \mathrm{~min}$ of growth in fresh media with succinate reaching a percentage of $7 \%$. This activity required only 50 metabolic enzymes as judged by our calculations. Metabolic routes essential for growth appeared to be silenced in this initial phase as judged by the fact that there was no increase in biomass. Only after the formation of the granules, did additional cellular metabolism occur, resulting in cell 
division and an exponential increase in cellular biomass. In this second phase, 218 enzymes are required as a minimum set of metabolic enzymes. PHB remained constant in this period at the initial level of $7 \%$.

Kojima and co-workers (Kojima et al. 2004) showed that the production of PHB in P. denitrificans is linked to acetyl-CoA levels, with higher levels leading to higher PHB production. The same authors reported that PHB synthesis in $P$. denitrificans is not transcriptionally regulated. The expression of the genes $p h a A$, phaB and phaC (Kojima et al. 2004), involved in PHB biosynthesis, is not repressed in presence of nitrogen, in contrast to other microorganisms, which only accumulate $\mathrm{PHB}$ when growth is arrested due to nitrogen limitation (Bordel et al. 2019a, b). Kojima et al. (2004) showed that the PHB biosynthetic genes were not repressed in presence of nitrogen, however, the PHB content of $P$. denitrificans cells decreased drastically when nitrogen was available. This drop of PHB was concomitant to a strong decrease in the cellular concentration of acetyl-CoA. These observations are consistent with our simulations. In conditions of exponential growth, most of the produced acetyl-CoA is drained into the TCA cycle, and, in lower amounts, to the synthesis of other metabolic precursors. This results in the depletion of the cellular pool of acetyl-CoA, which in turn causes a strong decrease in the rate of acetoacetyl-CoA synthesis by beta-ketothiolase (phaA). The same correlation between PHB accumulation and acetylCoA concentration was also observed by Olaya-Abril et al. (2018) in a mutant strain with increased PHB accumulation. The stoichiometry of beta-ketothiolase involving 2 acetyl-CoA molecules is likely to make its rate more sensitive to decreased acetyl-CoA concentrations (if the concentrations are below the enzyme saturation levels). For instance, a four-fold drop in the concentration of acetyl-CoA (as the one reported by Kojima and co-workers), would result in a 16-fold decrease of the rate of betaketothiolase, provided that the expression level of the enzyme remains the same. This fact could explain why citrate synthase outcompetes beta-ketothiolase under exponential growth conditions.

A good linear correlation between Nile Red staining and PHB content has been well established in many previous works using different bacteria (Gorenflo et al. 1999; Spiekermann et al. 1999; Zuriani et al. 2013). Our results are similar to the results of different fluorescence microscopy studies on PHB granule formation. For example, when PHB-free cultures of Azotobacter vinelandii or Caryophanon latum were transferred to fresh media with suitable carbon and energy sources, formation of visible fluorescent Nile Red stained structures appeared after 1 or $2 \mathrm{~h}$ of incubation (Hermawan and Jendrossek 2007; Jendrossek et al. 2007). PHB

accumulation was even fastest in $R$. eutropha cells, which needed only 10 min to accumulate PHB granules after transfer of PHB-free cells to a medium promoting PHB accumulation (Jendrossek 2009). This is of the same order of time in P. denitrificans cells.

Models in the literature for granule formation suggest that granules may arise through physical association of PHB oligomers forming micelle-like structures or by budding off the plasma membrane, resulting in a granule covered with a monolayer of lipid (Jendrossek 2009). It has been observed that the distribution of PHB granules in Rhodospirillum rubrum and $R$. eutropha occurred near the cell poles and near the cell wall (Jendrossek 2009). Indeed, we occasionally observed a more regular distribution of the PHB granules in the $P$. denitrificans cells. We hypothesize that an equal distribution of PHB granules is required in dividing cells perhaps by using a division control mechanism of the PHB inclusions explaining the more organized distribution of the granules. Interestingly, $R$. rubrum cells exhibited a regular PHB granule distribution pattern as well with almost equal spacing between individual granules (Handrick et al. 2004), similar to what we observed in this study. In the literature, there are contradictory conclusions about the localization of the nascent PHB granules within the cell. In some cases, the granules appear dispersed randomly in the cytoplasm and in other cases, the nascent granules are shown to be attached to the inner leaflet of the plasma membrane (Tian et al. 2005). Future studies are required to get a more fundamental understanding of the organization of PHB granules in different species and at different phases of growth.

\section{Supplementary Information}

The online version contains supplementary material available at https://doi. org/10.1186/s13568-021-01273-X.

Additional file 1: Figure S1. Staining of P. denitrificans cells with MTG.
Details of dividing cells (at an OD 660 of about 0.75$)(\mathbf{A})$ and spheroplasts
(B) stained with $1 \mu \mathrm{M}$ MTG during 5 min at $34^{\circ} \mathrm{C}$ and imaged using LSCM
showing PHB granules distributed symmetrically. Figure S2. PHB inclu-
sions in P. denitrificans cells grown in a defined mineral salts medium with
$25 \mathrm{mM}$ succinate as the sole carbon and energy sources. A Growth curve
of the cells incubated at $34^{\circ} \mathrm{C}$ and 300 rpm and gas chromatographic data
of specific PHB production ( $\mu$ g PHB per mg of cell biomass). B At different
time points, $1 \mathrm{ml}$ of culture was incubated with $2 \mu \mathrm{M}$ of Nile Red during 5
min and imaged using LSCM. The images show the disappearance of PHB
inclusions at the stationary phase of growth and completely disappeared
after $34 \mathrm{~h}$ of cultivation.

Additional file 2: File S1. Excel with the list of these enzymes mentioned in the text.

Acknowledgements

Not applicable. 


\section{Authors' contributions}

FSB conceived the work. SB carried out the metabolic modeling calculations. FSB carried out the microscopy and biochemical analyses on PHB synthesis. RVS, SB and FSB interpreted the results and wrote the manuscript. All authors have read and approved the final manuscript.

\section{Funding}

This work was supported by the Regional Government of Castilla y León and the EU-FEDER (CLU 2017-09 and UIC 071). Dr. Fernando Santos-Beneit was supported at the Vrije Universiteit Amsterdam by a European Erasmus grant.

\section{Availability of data and materials}

The authors declare that all data obtained have been included into the manuscript, its Additional file 1, 2 and/or repositories.

\section{Declarations}

\section{Ethics approval and consent to participate}

This article does not contain any studies with human participants or animals.

\section{Consent for publication}

Not applicable.

\section{Competing interests}

All authors declare that they have no conflict of interest.

\section{Author details}

${ }^{1}$ Department of Chemical Engineering and Environmental Technology, School of Industrial Engineering, University of Valladolid, Dr. Mergelina, s/n, 47011 Valladolid, Spain. ${ }^{2}$ Institute of Sustainable Processes, Dr. Mergelina s/n, 47011 Valladolid, Spain. ${ }^{3}$ Department of Molecular Cell Biology, Faculty of Science, Vrije Universiteit Amsterdam, Amsterdam, The Netherlands.

Received: 20 July 2021 Accepted: 26 July 2021

Published online: 09 August 2021

\section{References}

Anderson AJ, Dawes EA (1990) Occurrence, metabolism, metabolic role, and industrial uses of bacterial polyhydroxyalkanoates. Microbiol Rev 54(4):450-472

Bordel S, Rojas A, Muñoz R (2019a) Reconstruction of a Genome Scale Metabolic Model of the polyhydroxybutyrate producing methanotroph Methylocystis parvus OBBP. Microb Cell Fact 18(1):104

Bordel S, Rodríguez Y, Hakobyan A, Rodríguez E, Lebrero R, Muñoz R (2019b) Genome scale metabolic modeling reveals the metabolic potential of three type II methanotrophs of the genus Methylocystis. Metab Eng 54:191-199

Dariš B, Knez Ž (2020) Poly(3-hydroxybutyrate): Promising biomaterial for bone tissue engineering. Acta Pharm 70(1):1-15

De Vries GE, Harms N, Hoogendijk J, Stouthamer AH (1989) Isolation and characterization of Paracoccus denitrificans mutants with increased conjugation frequencies and pleiotropic loss of a (nGATCn)-DNA-modifying property. Arch Microbiol 152:52-57

Ebrahim A, Lerman JA, Palsson BO, Hyduke DR (2013) COBRApy: constraintsbased reconstruction and analysis for python. BMC Syst Biol 7:74

Gorenflo V, Steinbüchel A, Marose S, Rieseberg M, Scheper T (1999) Quantification of bacterial polyhydroxyalkanoic acids by Nile red staining. Appl Microbiol Biotechnol 51(6):765-772

Handrick R, Reinhardt S, Schultheiss D, Reichart T, Schüler D, Jendrossek V, Jendrossek D (2004) Unraveling the function of the Rhodospirillum rubrum activator of polyhydroxybutyrate (PHB) degradation: the activator is a PHBgranule-bound protein (phasin). J Bacteriol 186(8):2466-2475

Harms N, De Vries GE, Maurer K, Veltkamp E, Stouthamer AH (1985) Isolation and characterization of Paracoccus denitrificans mutants with defects in the metabolism of one-carbon compounds. J Bacteriol 164(3):1064-1070

Hermawan S, Jendrossek D (2007) Microscopical investigation of poly(3-hydroxybutyrate) granule formation in Azotobacter vinelandii. FEMS Microbiol Lett 266(1):60-64
Jendrossek D (2005) Fluorescence microscopic investigation of poly(3-hydroxybutyrate) granule formation in bacteria. Biomacromol 6(2):598-603

Jendrossek D (2009) Polyhydroxyalkanoate granules are complex subcellular organelles (carbonosomes). J Bacteriol 191(10):3195-3202

Jendrossek D, Handrick R (2002) Microbial degradation of polyhydroxyalkanoates. Annu Rev Microbiol 56:403-432

Jendrossek D, Pfeiffer D (2014) New insights in the formation of polyhydroxyalkanoate granules (carbonosomes) and novel functions of poly(3-hydroxybutyrate). Environ Microbiol 16(8):2357-2373

Jendrossek D, Selchow O, Hoppert M (2007) Poly(3-hydroxybutyrate) granules at the early stages of formation are localized close to the cytoplasmic membrane in Caryophanon latum. Appl Environ Microbiol 73(2):586-593

Kojima T, Nishiyama T, Maehara A, Ueda S, Nakano H, Yamane T (2004) Expression profiles of polyhydroxyalkanoate synthesis-related genes in Paracoccus denitrificans. J Biosci Bioeng 97(1):45-53

Olaya-Abril A, Luque-Almagro VM, Manso I, Gates AJ, Moreno-Vivián C, Richardson DJ, Roldán MD (2018) Poly(3-hydroxybutyrate) hyperproduction by a global nitrogen regulator NtrB mutant strain of Paracoccus denitrificans Pd1222. FEMS Microbiol Lett 365(1):251

Overbeek R, Begley T, Butler RM, Choudhuri JV, Chuang HY, Cohoon M, de CrécyLagard V, Diaz N, Disz T, Edwards R, Fonstein M, Frank ED, Gerdes S, Glass EM, Goesmann A, Hanson A, Iwata-Reuyl D, Jensen R, Jamshidi N, Krause L, Kubal M, Larsen N, Linke B, McHardy AC, Meyer F, Neuweger H, Olsen G, Olson R, Osterman A, Portnoy V, Pusch GD, Rodionov DA, Rückert C, Steiner J, Stevens R, Thiele I, Vassieva O, Ye Y, Zagnitko O, Vonstein V (2005) The subsystems approach to genome annotation and its use in the project to annotate 1000 genomes. Nucleic Acids Res 33(17):5691-5702

Overbeek R, Olson R, Pusch GD, Olsen GJ, Davis JJ, Disz T, Edwards RA, Gerdes S, Parrello B, Shukla M, Vonstein V, Wattam AR, Xia F, Stevens R (2014) The SEED and the rapid annotation of microbial genomes using subsystems technology (RAST). Nucleic Acids Res 42(D1):D206-214

Potter M, Steinbüchel A (2005) Poly(3-hydroxybutyrate) granule-associated proteins: impacts on poly(3-hydroxybutyrate) synthesis and degradation. Biomacromol 6(2):552-560

Reinecke F, Steinbüchel A (2009) Ralstonia eutropha strain H16 as model organism for PHA metabolism and for biotechnological production of technically interesting biopolymers. J Mol Microbiol Biotechnol 16(1-2):91-108

Spiekermann P, Rehm BH, Kalscheuer R, Baumeister D, Steinbüchel A (1999) A sensitive, viable-colony staining method using Nile red for direct screening of bacteria that accumulate polyhydroxyalkanoic acids and other lipid storage compounds. Arch Microbiol 171(2):73-80

Steinbüchel A, Aerts K, Babel W, Follner C, Liebergesell M, Madkour MH, Mayer F, Pieper-Furst U, Pries A, Valentin HE (1995) Considerations on the structure and biochemistry of bacterial polyhydroxyalkanoic acid inclusions. Can J Microbiol 41(Suppl 1):94-105

Tian J, Sinskey AJ, Stubbe J (2005) Kinetic studies of polyhydroxybutyrate granule formation in Wautersia eutropha H16 by transmission electron microscopy. J Bacteriol 187(11):3814-3824

Ueda S, Matsumoto S, Takagi A, Yamane T (1992) Synthesis of poly(3-hydroxybutyrate-co-3-hydroxyvalerate) from methanol and n-amyl alcohol by the methylotrophic bacteria Paracoccus denitrificans and Methylobacterium extorquens. Appl Environ Microbiol 58(11):3574-3579

Van Verseveld HW, Boon JP, Stouthamer AH (1979) Growth yields and the efficiency of oxidative phosphorylation of Paracoccus denitrificans during two-(carbon) substrate-limited growth. Arch Microbiol 121:213-223

Vida TA, Emr SD (1995) A new vital stain for visualizing vacuolar membrane dynamics and endocytosis in yeast. J Cell Biol 128(5):779-792

Zúñiga C, Morales M, Le Borgne S, Revah S (2011) Production of poly- $\beta$ hydroxybutyrate $(\mathrm{PHB})$ by Methylobacterium organophilum isolated from a methanotrophic consortium in a two-phase partition bioreactor. J Hazard Mater 190(1-3):876-882

Zuriani R, Vigneswari S, Azizan MNM, Majid MIA, Amirul AA (2013) A high throughput Nile red fluorescence method for rapid quantification of intracellular bacterial polyhydroxyalkanoates. Biotechnol Bioprocess Eng 18:472-478

\section{Publisher's Note}

Springer Nature remains neutral with regard to jurisdictional claims in published maps and institutional affiliations. 